\title{
Activación de encuadres en red. Un modelo para repensar la circulación de sentidos en el nuevo entorno mediático
}

\author{
Network activated frames. A model to rethink the \\ circulation of senses in the new media environment
}

\author{
Natalia Aruguete
}

Cómo citar este artículo:

Aruguete, Natalia (2021). "Activación de encuadres en red. Un modelo para repensar la circulación de sentidos en el nuevo entorno mediático". Profesional de la información, v. 30, n. 2, e300218.

https://doi.org/10.3145/epi.2021.mar.18

Artículo recibido el 30-10-2020

Aceptación definitiva: 04-02-2021

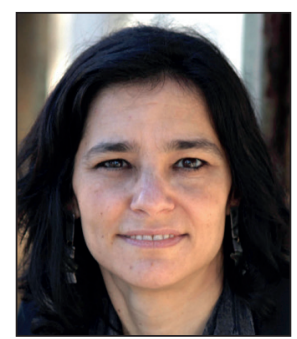

Natalia Aruguete

https://orcid.org/0000-0002-1571-9224

Consejo Nacional de Investigaciones Cientificas y

Técnicas de Argentina (Conicet)

Universidad Nacional de Quilmes

Castro Barros, 981 pb 2

Buenos Aires C1217ABI, Argentina

nataliaaruguete@gmail.com

\section{Resumen}

Este trabajo propone un nuevo modelo de activación de encuadres llamado network activated frames (NAF) (activación de encuadres en red). El NAF busca actualizar el estudio del framing como resultado de la activación de encuadres por parte de los usuarios en una red conectada. Con este objetivo en mente, reconstruyo las distintas nociones de frame y framing en la bibliografía en comunicación política y presento sus limitaciones. La activación de encuadres en redes sociales se constata experimentalmente utilizando tweets apareados (conjoint experiment), una técnica que rota aleatoriamente una variedad de elementos de encuadre (frame elements) y evalúa la intención de compartir el contenido. Los resultados proporcionan evidencia concluyente de la propensión de los usuarios de redes sociales a activar distintos elementos de encuadre en distintas regiones de una red social.

\section{Palabras clave}

Framing; Activación en cascada; Redes sociales; Covid-19; Riesgo; Experimento de tweets apareados; Atención selectiva; Twitter; Activación de encuadres en red; Cámaras de eco.

\begin{abstract}
This work proposes a new model of activation of frames, called network activated frames (NAF). The NAF seeks to update the study of framing as a result of the activation of frames by users in a connected network. With this objective in mind, I reconstruct the different notions of frame and framing in the political communication literature and present their limitations. The activation of frames in social networks is verified experimentally using a conjoint experiment, a technique that randomly rotates a variety of frame elements and evaluates the intention to share the content. The results provide conclusive evidence of the propensity of social network users to activate different frame elements in different regions of a social network.
\end{abstract}

\section{Keywords}

Framing; Cascading activation; Social media; Covid-19; Risk; Conjoint experiment; Selective attention; Twitter; Network activated frames; Echo chambers. 
Financiación

Esta investigación es parte del proyecto Transparencia, confianza y redes sociales, 1300600-01-PEC. PI: Ernesto Calvo, 2019-2020, del Banco Interamericano de Desarrollo.

\section{Agradecimiento}

Agradezco los valiosos comentarios que han hecho los investigadores Ernesto Calvo y Tiago Ventura a una primera versión de este trabajo; quedan exentos de cualquier responsabilidad respecto a los errores y omisiones que pudieran existir.

\section{Introducción}

El objetivo de este trabajo es doble. Por un lado, analizar al framing como "programa de investigación" (D’Angelo, 2002; 2012) y discutir la noción de integralidad desde la mirada de distintos autores. Por otro, proponer un nuevo modelo de activación de encuadres - "activación de encuadres en red" (network activated frames - NAF)- que ayude a comprender la propagación de marcos interpretativos en el actual ecosistema comunicacional, donde los medios digitales y las redes sociales virtuales tienen un fuerte protagonismo en la puesta en circulación de discursos que estructuran el mundo social.

El proceso framing en redes sociales disputa concepciones existentes, dado que la decisión de un emisor de proponer un determinado marco para definir un asunto (topic) no garantiza que el resto de los usuarios lo observen. Para que se conformen encuadres en distintas regiones de la red es necesario que los usuarios activen mensajes que son ofrecidos -no impuestos- por autoridades de la red social ${ }^{1}$ (Aruguete; Calvo, 2018). Activar un mensaje (por ejemplo, compartir en Facebook, comentar, retweetear o dar "like" en Twitter) habilita dicho contenido en nuestro muro y en el de nuestros pares en línea.

El modelo de activación de encuadres en red (NAF, según sus siglas en inglés) permite explicar dos caras de la misma moneda digital:

- los encuadres en redes sociales se construyen colectivamente a partir de decisiones individuales de los usuarios de aceptar y activar aquellos elementos de encuadre (frame elements) (Matthes; Kohring, 2008) que tienen resonancia con sus "mundos de la vida"2 virtuales;

- estas decisiones individuales de activar selectivamente determinados contenidos -condicionadas por estructuras topológicas- cambian la frecuencia de las imágenes, palabras, hashtags e hipervínculos que los usuarios observan en distintas regiones de la red. Ello permite entender por qué los encuadres se estructuran localmente, de manera dinámica y reticular (Aruguete, 2019).

La organización de este artículo es la siguiente: primero se describen las nociones de frame y framing en el campo de la comunicación política, con énfasis en las ventajas de esta teoría para explicar el acto comunicacional, así como en sus limitaciones cuando los mensajes son distribuidos en red. Luego se discuten las nociones de integralidad e interactividad del framing process desde distintas miradas. En la tercera sección se introduce el modelo de activación en cascada tal como ha sido propuesto inicialmente por Entman $(2003 ; 2004)$-esto es, cuando la información es emitida por autoridades políticas y activada por medios tradicionales- y revisada tiempo después (Entman; Usher, 2018). En la cuarta sección se introduce el modelo de activación en cascada en red (NAF) según el cual el proceso de activación de contenidos se da en contextos de comunicación entre pares (peer-to-peer) que mantienen dinámicas locales de activación de sentido en red. Para ejemplificar la activación en cascada en red, la sección cinco presenta un experimento de tweets apareados (conjoint experiment), que evidencia cómo la activación de elementos de encuadre por parte de los usuarios tiene consecuencias topológicas sobre la circulación de mensajes en distintas regiones de la red social (Calvo; Aruguete, 2020). El artículo concluye con una discusión sobre el modelo de activación en cascada como agenda de investigación.

\section{El framing como programa integral y multiparadigmático}

Framing y frame ${ }^{3}$ son palabras clave de la investigación en comunicación política, aunque sus primeras conceptualizaciones provienen de otros campos de investigación, tales como la psicología cognitiva y la sociología interpretativa. Dentro de esta última, el interaccionismo simbólico, la fenomenología y la etnometodología aportaron las primeras exploraciones.

El antropólogo Bateson (2000) propuso, a mediados del siglo pasado, el concepto de frame como una herramienta de la psique que permite explicar por qué la gente centra su atención en determinados aspectos de la realidad y desestima otros. Tiempo después, el sociólogo Goffman redefinió el significado de encuadre

“desde lo individual a lo colectivo, desde lo psicológico a lo sociológico" (Ardèvol-Abreu, 2015, p. 429).

Imposibilitados de comprender el mundo en su totalidad, propone Goffman (2006), los individuos clasifican, interpretan y definen situaciones de acuerdo con determinados principios de organización que gobiernan los eventos y, más aún, su relación subjetiva con ellos ${ }^{4}$. En otras palabras, 
"Ias personas, por lo tanto, no responden directamente a los hechos objetivos, sino que lo hacen con referencia a su interpretación" (Sádaba, 2008, p. 25).

Desde el campo de la comunicación política, el framing se concibe como un proceso dinámico, integral y activo de producción, circulación y reproducción de significados socialmente compartidos y persistentes en el tiempo. Los frames, por su parte, toman forma en distintas etapas de ese proceso como patrones de comprensión, percepción y definición de las situaciones sociales que están presentes en las comunicaciones estratégicas de los actores políticos y organizacionales, y en las estructuras cognitivas de los periodistas y sus criterios rutinarios de selección de la información (Reese, 2007). Los encuadres que subyacen a los textos noticiosos son co-construidos tanto por quienes exhiben como por quienes interpretan los asuntos públicos en un proceso dinámico e interactivo. Dentro de los esquemas de pensamiento existentes, la mente humana categoriza aquello que se estimula en el contacto con los encuadres presentes en un mensaje. Como lo expresa James (1869), la activación de determinados esquemas de pensamiento por parte de los sujetos, a partir de los enfoques que ofrece un texto, depende de que esos encuadres tengan resonancia y no contradigan sus conocimientos previos.

Diversos investigadores trabajan en pos de dotar al framing de una mayor solidez teórica y capacidad operativa. En ese esfuerzo, D’Angelo (2012) discute la noción de "paradigma fracturado" de Entman (1993) al madurar la concepción integral desde una doble acepción: la de "reunir" y la de "encajar". Gran parte de los investigadores ven al framing como un proceso capaz de reunir todas las instancias de la comunicación en un mismo estudio (D’Angelo, 2002; Matthes, 2012; Matthes; Kohring, 2008). D’Angelo (2012) añade una segunda acepción: “encajar en" significa asignar conceptos y diseñar procedimientos metodológicos enfocados en diversas etapas del proceso de circulación de sentido, de manera que tales conceptos y procedimientos encajen en un programa de investigación multiparadigmático, cuyo propósito es refinar teorías específicas con el objeto de producir hallazgos de aproximaciones empíricas particulares enmarcadas en un núcleo común de conjeturas.

Así entendido, el framing process puede ser analizado desde los tres paradigmas endémicos de la investigación en comunicación -el cognitivo, el constructivista y el crítico- con el objeto de alcanzar cuatro objetivos empíricos:

- identificar los marcos como unidades temáticas;

- indagar en qué condiciones se producen tales frames;

- examinar en qué medida activan e interactúan con el conocimiento previo de un individuo al afectar sus interpretaciones, evaluaciones y toma de decisiones;

- analizar de manera holística los procesos sociales de formación de cosmovisiones alrededor de las cuestiones políticas.

El paradigma cognitivo del framing se enfoca en la influencia de los encuadres presentes en los mensajes, más propiamente en la "activación del conocimiento" (knowledge activation process) que los textos generan sobre los esquemas individuales (Price; Tewksbury, 1997). El efecto framing atiende a la capacidad de ciertos atributos de los mensajes (su organización, selección de contenido o estructura temática) de estimular pensamientos particulares para la evaluación de cuestiones políticas o de otro tipo. Esencia del framing effect, el modelo de la aplicabilidad sugiere que las ideas aplicables entran en competencia con lo que ya está en la mente de los lectores o espectadores. Esas ideas y conceptos se anidan entre sí aunque sus enlaces no formen una jerarquía predeterminada; se trata de "jerarquías enredadas" (Anderson, 1983), de manera que las construcciones pueden tener una posición distinta y múltiple en las subredes que se conformen alrededor de un asunto o contexto determinado. Como consecuencia, los individuos dejan ingresar determinados dispositivos narrativos a su conocimiento previo y permiten que los esquemas se actualicen y/o se modifiquen; estas construcciones del conocimiento actualizadas pueden usarse, además, para completar los vacíos informativos. En esa interacción, los encuadres que tengan resonancia activarán pensamientos aplicables, al tiempo que las ideas e imágenes que se vean relegadas respecto del marco dominante se modificarán.

¿Cuál es el potencial de los marcos interpretativos de los textos para volver aplicables y, por lo tanto, activar elementos distintivos de los conocimientos almacenados en la memoria de los lectores? Es posible distinguir entre la influencia inmediata de un mensaje, esto es las evaluaciones realizadas durante o inmediatamente después de su procesamiento, y aquellas que quedan almacenadas en la memoria y se actualizan en algún momento posterior, ya sea debido a la accesibilidad residual o porque algún otro estímulo las asocia (Hastie; Park, 1986). En otras palabras, los efectos de encuadre pueden permanecer latentes y ser preactivados (primed) tiempo después, mediante mecanismos de accesibilidad posteriores. La "accesibilidad" se refiere al potencial de acumulación del conocimiento disponible, que dependerá, al menos en parte, del nivel de energía o "excitación" asociado con esa construcción (Higgins, 1989, citado en Price; Tewksbury, 1997). La ventaja de incluir el principio de propagación de la activación del conocimiento en el análisis del framing desde el paradigma cognitivo es que permite comprender la influencia de los encuadres de los textos. Sugiere que, al focalizar (activar) un elemento particular (nodo) en una red, esa activación se irradiará desde ese nodo a otros con los que está asociado y ello, a su vez, resultará en un aumento de la probabilidad de que también se activen esos otros elementos.

\section{Se propone el network activated frames (NAF), un modelo productivo para com- prender la activación en cascada como un proceso de composición colectiva de encuadres que resulta de las reacciones individuales de usuarios conectados a una red}


Desde el paradigma crítico, los frames son concebidos como modelos persistentes de conocimiento, interpretación y presentación por medio de los cuales quienes detentan poder social y político organizan el discurso verbal y/o visual (Gitlin, 2003). Para analizar el poder de los discursos es necesario atender al contexto político y socio-cultural en el que estos encuadres nacen, se desarrollan y dejan huellas en los textos. Dentro de este paradigma, una línea de investigación busca conocer el proceso de construcción de los encuadres (frame-building) al enfocarse en la relación entre gobiernos, elites políticas y medios, desde la teoría de la hegemonía, la teoría del Indexing (Bennett, 1996) y el modelo de la activación en cascada (Entman, 2003; 2004). La otra atiende a la relación que distintos colectivos sociales establecen con los medios de comunicación como forma de acceder al conocimiento público (Gitlin, 2003). Me detendré en la primera de ambas, en vistas de uno de los objetivos de este estudio.

Desde los enfoques centrados en el nexo entre gobierno y medios, Entman advierte que la hegemonía no alcanza para explicar la complejidad de ciertos fenómenos ya que sus parámetros analíticos no incluyen el disenso tanto político cuanto discursivo. En ese marco, los medios son percibidos como entidades subordinadas a los gobiernos y a otras elites políticas. Ergo, el abanico de temas y fuentes de información se estructurará dentro de los límites fijados por la visión dominante de dichos gobiernos y elites acerca de un asunto.

La Hegemonía entiende que la deliberación y la influencia democráticas son casi imposibles dados los estrechos límites ideológicos existentes en la información que los gobiernos ponen a disposición del público. Aun cuando entran en conflicto, las elites políticas mantienen una armonía que impide el flujo de información independiente (Entman, 2004). La teoría del Indexing advierte que la variedad de voces se circunscribe a la amplitud del espectro de opiniones existentes en las elites políticas. La perspectiva del Indexing sí incorpora el disenso como resquicio para la introducción de otras voces. En tales ocasiones, sin embargo, los medios, lejos de criticar la palabra oficial, actúan como un "vehículo" de la discordancia surgida entre los gobiernos y otros actores jerárquicos (Bennett, 1990; 1996). Por ello, Entman postula que el Indexing tampoco logra dar cuenta de las causas de los desacuerdos, menos aún de los mecanismos discursivos que se activan para articular tales disonancias en los distintos estratos del sistema comunicacional. En su lugar, propone el modelo de activación en cascada para comprender qué ocurre y cómo se organizan las discrepancias que surgen en el interior de las elites políticas. Desarrollaré más extensamente este modelo en el próximo apartado.

El paradigma constructivista del framing process es el más interactivo de los tres. Enmarcados en sus rutinas productivas, los periodistas u otros emisores procesan información y, al hacerlo, crean "paquetes de herramientas" (D’Angelo, 2002) con los que interactúan audiencias activas durante sus propios procesos de percepción e interpretación de los asuntos públicos (Reese, 2007). Los periodistas seleccionan y dan visibilidad a ciertos aspectos de una realidad al construir noticias (Ardèvol-Abreu, 2015) mediante paquetes de encuadre conformados "por una serie de símbolos condensadores de base cultural” (López-Rabadán; Vicente-Mariño, 2013, p. 247). La noticia, sin más, es una construcción social (Tuchman, 1983).

Gracias a los estrechos puntos de contacto que mantiene con la perspectiva fenomenológica de construcción social de la realidad (Berger; Luckmann, 1991), el constructivismo parece acoger mejor que las otras miradas la noción de integralidad en sus dos acepciones: por un lado, habilita una mirada comprensiva del proceso de encuadre en el sentido de reunir y, por el otro, promueve la producción de estudios centrados en distintas etapas de la comunicación de manera que encajen en un programa más amplio (Koziner, 2015).

\section{Activación en cascada: un puente hacia el framing process en el nuevo entorno mediático}

En Projection of power, Entman (2004) analiza la capacidad que tienen los marcos interpretativos de activarse y propagarse en un sistema comunicacional estratificado; se inician en los gobiernos, pasan por la red de élites no administrativas y siguen su rumbo a través de las empresas de noticias y sus textos hasta alojarse en los esquemas de percepción del público. La pregunta es: esos frames, ¿̇llegan intactos a la base social o, en cambio, es posible promover interpretaciones que se inicien en los niveles inferiores de ese sistema y desafien la palabra gubernamental?

Encuadrar significa definir efectos o condiciones como problemáticas, identificar sus causas, transmitir un juicio moral y promover un remedio o emitir un pronóstico. Cuando el marco interpretativo de un mensaje coincide con los esquemas habituales de un lector, las palabras e imágenes que articula se vuelven notables, comprensibles, memorables y emocionalmente resonantes (Entman, 2004). Por otro lado, para que un marco tenga resonancia al cubrir eventos, asuntos y actores políticos, es esencial la presencia de al menos dos de las cuatro funciones (elementos de encuadre) mencionadas más arriba. La primera es la definición de la situación, que activa los otros dos componentes del marco (transmite las causas implícitas del problema y el juicio moral), y la última es el remedio o la mejora futura (Entman, 2004).

Uno de los casos narrados por Entman tiene su punto de partida en el encuadre creado por George Bush (h.) después del 11-S, quien enfocara el evento como un "acto de guerra del demoníaco Osama bin Laden". Ese enunciado intentaba unir a los ciudadanos estadounidenses al presentar los hechos del 11-S desde un encuadre bélico y resaltar el carácter místico de Bin Laden. Los medios, por su parte, activaron selectivamente algunos de esos elementos e ignoraron otros que para el gobierno eran clave. Al hacerlo, alteraron la "sensación" de realidad (James, 1869) que intentó instalar Bush.

Algunos actores -los medios tradicionales u otras elites políticas- detentan el poder necesario para bloquear contenidos 
(ideas) en su tránsito desde el gobierno a la conciencia pública. Ahora bien, para crear un contra-encuadre no alcanza con cuestionar la palabra oficial con bocados de información dispersos. Es imprescindible promover palabras e imágenes notables, relevantes y culturalmente resonantes, que logren cubrir las funciones del frame propuestas por Entman; sólo así serán internalizadas como una alternativa coherente al marco que cuestionan (Entman, 2004).

Aunque enfocado en las relaciones de poder entre gobiernos y medios, el modelo de activación en cascada (Entman, 2003; 2004) ha demostrado ser uno de los esfuerzos más logrados por analizar el proceso de encuadre desde una concepción integral. No obstante, en su estudio del 11-S, la activación selectiva de ciertos elementos de encuadre y el consecuente desafío a la interpretación oficial discurren en un sistema comunicacional jerárquico, compuesto por niveles. El propio autor propuso revisar ese modelo lineal frente a la maduración del escenario mediático y reemplazarlo por el Cascading network activation model (Modelo de activación en cascada en red) para comprender cómo las características de la digitalización afectan las relaciones simbólicas de poder entre las elites, los medios de comunicación tradicionales y los individuos (Entman; Usher, 2018).

En este punto, me permito disentir con Entman respecto de la dinámica que adquiere la configuración de frames en el nuevo ecosistema comunicacional. La circulación de mensajes en redes sociales no se corresponde con una lógica estratificada sino con una dinámica reticular que produce combinaciones singulares de distintos tipos de contenidos en regiones de la red disímiles y, por ende, conforma marcos interpretativos en función del grado de atención y activación de información creada por emisores de los más variados. En el próximo apartado explicaré en qué consiste este juego de circulación de mensajes y su consencuente formación de frames locales (Aruguete; Calvo, 2018), con el propósito último de justificar la necesidad de incorporar un modelo actualizado de activación de encuadres en red (network activated frames) al análisis de la interación en redes sociales virtuales, con especial énfasis en la red Twitter.

\section{Activación de narrativas en redes sociales}

Los intercambios de mensajes entre los actores que habitan las redes sociales -los partidos políticos y sus candidatos, los funcionarios públicos, los grupos de interés, los medios masivos de comunicación, los periodistas y los usuarios plebeyos- dan cuenta de las expresiones políticas y las definiciones públicas sobre los asuntos de interés y, derivado de ello, del posicionamiento ideológico de las elites como el de sus seguidores (Barberá, 2015; Barberá; Rivero, 2012). Entre esos usuarios, la interacción no sigue una lógica jerárquica predeterminada sino que se traba en función de jerarquías enredadas, tal como refiere Anderson (1983). Como explicaré en esta sección, la mirada integral del framing process convive con una circulación reticular de contenidos, que se deriva de motivaciones individuales cuanto de consecuencias estructurales en las redes sociales, en la medida en que tales decisiones cambian la frecuencia de circulación de contenidos en distintas regiones de la red conformando comunidades virtuales.

En ese nivel subjetivo, la proximidad entre usuarios virtuales resulta de las actitudes de los individuos de integrarse a estructuras homogéneas y unirse a comunidades y colectivos con los cuales comparten valores, intereses e historias de vida similares. ¿Qué mueve a una persona a integrarse a estas comunidades de iguales? En los últimos años, diversos investigadores incorporaron el concepto de "polarización afectiva" (Iyengar et al., 2019; Mason, 2013; 2015) para explicar alineamientos entre distintos atributos de los individuos que exceden su comprensión racional del mundo político y los vuelve más homogéneos entre sí. Las uniones entre quienes comparten identidades políticas -como una de las expresiones de polarización afectiva- tienen efectos más significativos sobre ciertas emociones, entre ellas el odio, que sobre el posicionamiento racional alrededor de un asunto determinado.

Estos patrones subjetivos de asociación homofílica tienen una contraparte estructural en las redes sociales, ya que devienen interconexiones densas a nivel local al tiempo que condicionan el comportamiento de los usuarios (Barberá, 2015). En este nivel, el funcionamiento topológico de estas plataformas expresa el modo en que los usuarios (nodos) están interconectados mediante aristas (retweet, responder, like) que modelan la relación entre ellos: el nodo B se relaciona con el nodo A mediante una actividad (like, responder, retweet) que los vincula (Aruguete, 2019). De allí que la formación de comunidades se explique tanto por la lógica orgánica de la red (topología de red) como por el comportamiento subjetivo de los usuarios (la congruencia o disonancia cognitiva) en cuyos esquemas psíquicos se activan determinados trenes de pensamiento en detrimento de otros.

La "atención selectiva" (Himelboim; Smith; Shneiderman, 2013) en redes sociales indica que prestamos atención a algunos usuarios y temas en perjuicio de otros usuarios a los que podríamos seguir e infinidad de asuntos con los que tendríamos oportunidad de interactuar. Dicha atención selectiva deviene "cámara de eco", es decir que los algoritmos virtuales sistematizan nuestras decisiones, identifican los trending topics y nos entregan mensajes segregadamente de manera que estos mantengan una consistencia política e ideológica con nuestras ideas y preferencias (Aruguete; Calvo, 2018; Barberá, 2015).
La atención selectiva en redes sociales deviene cámara de eco, es decir que los algoritmos virtuales sistematizan nuestras decisiones, identifican los trending topics y nos entregan mensajes segregadamente, de manera que estos mantengan una consistencia política e ideológica con nuestras ideas y preferencias 
Pero no todos los estudios encuentran una relación estable entre polarización y burbujas de filtro en el escenario digital. Algunos autores lo atribuyen al tipo de tema que activa la interacción y el intercambio de información. Para Cardenal et al. (2019), los usuarios no están polarizados al analizar el consumo de noticias y medios. Este argumento es consistente con los resultados de Rojas, Barnidge y Abril (2016) y de Yang et al. (2016), quienes asocian la polarización con el tipo de contexto sociocultural o político del que se trate. Concretamente, muestran que los ciudadanos forjan relaciones singulares entre el uso que hacen de los medios tradicionales y digitales y la polarización percibida como de actitudes ${ }^{5}$. Más importante aún, la naturaleza simplista, controversial y extremista de las coberturas noticiosas tiene implicaciones en la propia percepción del sesgo mediático (Rojas; Barnidge; Abril, 2016). En definitiva, la hipótesis de que los internautas viven en cámaras de eco no es una invariante.

En este mapa de relaciones, Barberá (2015) ha constatado que la decisión de un sujeto de seguir a otro tiene costos subjetivos y estructurales. Si el contenido al que es expuesto -como resultado de decisiones previas- desafía sus creencias, puede crear disonancia cognitiva (Festinger, 1962) y debilitar la estructura de la red local a la que pertenece. Esa disonancia cognitiva genera, además, costos de oportunidad al reducir la probabilidad de que estemos expuestos a otro tipo de mensajes. En otras palabras, quienes estén ideológicamente más cerca también estarán topológica y virtualmente conectados entre sí. En estos casos, la red primaria de conexiones entre usuarios conforma comunidades: distingue grupos en función de su posicionamiento político y conecta a los actores de peso -que llamamos "autoridades"- con el universo de los usuarios de bajo rango que los rodean. En el interior de las comunidades, las palabras, los recursos retóricos y las imágenes que componen un encuadre se distinguen por su capacidad de vivificar sentimientos de respaldo o desacuerdo en el marco de un conflicto político. Cuanta mayor resonancia y visibilidad tenga un encuadre, más probable es que evoque pensamientos similares entre sus interlocutores.

Las reglas de usabilidad en Twitter establecen que un contenido que es retweeteado quedará publicado en el muro de los contactos. También aquí la activación en cascada en redes sociales sugiere que los mensajes con los que acordamos y, por ende, compartimos (retweet), serán habilitados -es decir, activados- en los muros de nuestros seguidores ${ }^{6}$. Al activar determinadas publicaciones en los muros de nuestros amigos modificamos la frecuencia y la velocidad con la que esos contenidos circulan. Es decir que la activación de determinados mensajes por parte de los usuarios propaga frame elements que difieren de aquellos que circulan en otras regiones de la red. Los elementos de encuadre derivan de la combinación de contenidos habilitados en el muro de los usuarios, que realzan aspectos de un evento mediático: causan una interpretación, evaluación y/o solución que apoyan su alineamiento con algunos usuarios y justifican su oposición con otros (Aruguete, 2019). Como contracara, los mensajes que no coincidan con tales esquemas lejos de activarse quedarán bloqueados y, por ende, su difusión se verá desalentada en esa región de la red.

\section{Dos mensajes y una viralización: Evaluación experimental del NAF}

¿Cómo entender la activación selectiva de encuadres en redes sociales? Consideremos el siguiente ejercicio conceptual: un usuario conservador observa la misma noticia publicada en dos tweets que, con igual probabilidad, aparecen en su muro. El primer tweet es publicado por un medio progresista mientras que el segundo es publicado por un medio conservador; ambos describen el mismo evento y, para simplificar este ejemplo, con idéntico texto. El usuario está interesado en la noticia y la comparte en su muro. Dada su inclinación política, aun cuando ambos textos son idénticos, publica con mayor probabilidad el tweet del medio conservador (por ejemplo, un $70 \%$ de las veces). La noticia es habilitada en el feed de sus amigos, quienes observan el tweet del medio conservador con mayor frecuencia, un $70 \%$ de las veces en lugar de un 50\%. Ahora imaginemos el mismo proceso muchas veces y pensemos en la cantidad de contenidos que son activados selectivamente, alterando las frecuencias con las que son re-publicados y observados distintos elementos de encuadre.

El ejemplo anterior, replicado experimentalmente mediante tweets apareados (conjoint experiment), muestra el mecanismo mediante el cual cambian las frecuencias con las que observamos distintos contenidos en las redes sociales. Las burbujas de filtro en redes sociales (Pariser, 2011) aluden al proceso mediante el cual (1) los contenidos y (2) las preferencias de los usuarios que habitan una misma región de la red se vuelven localmente homogéneas. Esto es: ¿̇en qué medida los contenidos publicados por usuarios validan y amplifican encuadres que resuenan con los de sus pares conectados? Producto de la dinámica topológica de estas plataformas, los algoritmos virtuales observan y sistematizan los contenidos con los que interactúan los usuarios que luego son distribuidos de manera segregada para consolidar y aumentar las preferencias detectadas (Calvo; Aruguete, 2020).

La existencia de verdaderas "burbujas" en redes sociales a menudo confunde dos discusiones que son conceptualmente distintas. La primera discusión se pregunta en qué medida diferentes elementos de encuadre son observados en distintas regiones de las redes sociales. Es decir, busca distinguir si existen cambios en las frecuencias con las que distintos usuarios observan contenido que es ideológicamente congruente con sus preferencias. Respecto de este primer problema -“¿es la información localmente distinta?”- la evidencia que favorece una respuesta positiva es abrumadora. Los contenidos activados en distintas regiones de una red social son distintos tanto en los análisis que critican la noción de "burbuja" como en aquellos que la aprueban (Theocharis et al., 2020; Yang et al., 2020). 
La segunda discusión busca dilucidar si las diferencias existentes en la frecuencia de los contenidos observados por los usuarios en distintas regiones de la red provoca un cambio de preferencia o un cambio en los contactos que son seleccionados ("amigos"), lo cual volvería a las redes ideológicamente homogéneas. Quienes encuentran evidencia contraria a la existencia de "burbujas" reportan que las redes sociales no necesariamente producen un cambio de actitud y que, por ende, no va de suyo que los individuos sólo busquen amigos que piensen como ellos (Bakshy; Messing; Adamic, 2015; Barberá, 2015). En efecto, las redes pueden crear regiones donde la información publicada es ideológicamente congruente sin que existan cambios de actitud por parte de los usuarios y sin que se produzcan modificaciones en nuestros contactos.

Por otro lado, si aceptamos que los frames generan un cambio de actitud, lo cual ha sido probado experimentalmente tanto en el área de comunicación como en el de psicología política (Kahneman, 2011), podemos esperar que diferencias en el encuadre que predomina en distintas regiones tenga, a su vez, consecuencias sobre las decisiones y actitudes de los usuarios.

\subsection{Objetivo del experimento}

El experimento que se presenta a continuación fue diseñado para dar una respuesta concluyente a la primera de las dos discusiones citadas arriba. El objetivo del conjoint experiment es describir el cambio en las frecuencias de los contenidos observados en distintas regiones de la red. Es decir, busca constatar el cambio en la conformación de encuadres en red que depende de la decisión de los usuarios de activar (compartir) contenidos y habilitarlos entre sus contactos. $\mathrm{A}$ diferencia del modelo tradicional del proceso framing, la conformación de encuadres locales depende de que usuarios localizados en distintas regiones de una red social acepten y compartan contenidos con distinta probabilidad. Por ello, para observar y medir la frecuencia con que distintos elementos de encuadre son activados por los usuarios, se describe a continuación un experimento de encuesta (conjoint experiment), una versión adaptada de encuadres en competencia (Chong; Druckman, 2007), que permite observar cómo las decisiones individuales de activar elementos de encuadre que son cognitivamente congruentes cambian la frecuencia con la que tales contenidos circulan en una comunidad virtual.

El conjoint experiment ha sido utilizado en investigaciones tendientes a medir las actitudes políticas hacia

- la inmigración (Hainmueller; Hopkins, 2014);

- los atributos de los candidatos y las propuestas de campaña (Franchino; Zucchini, 2015; Horiuchi; Smith; Yamamoto, 2017);

- las políticas de rescate de la Eurozona (Bechtel; Hainmueller; Margalit, 2014);

- el cambio climático (Bechtel; Scheve, 2013).

La ventaja que tiene sobre la encuesta estándar es que mide de manera desagregada la relevancia que los distintos aspectos contenidos en el experimento tienen para el encuestado. Esta técnica, complementaria de los datos observacionales de Twitter, procura sortear el problema planteado por Wojcieszak et al. (2016), quienes apuntan a las limitaciones de las encuestas y los experimentos para constatar la hipótesis de la exposición selectiva, por cuanto carecen de la validez externa que permitiría conocer el comportamiento de las personas en situaciones de la vida real.

Existen diversas maneras de realizar experimentos de encuesta para establecer la propensión a compartir mensajes publicados en las redes sociales. En este estudio se recurre a la técnica del conjoint experiment porque permite detectar el efecto del componente marginal promedio para cada uno de los atributos que componen el tweet sobre la preferencia de los encuestados (Horiuchi; Smith; Yamamoto, 2017). Concretamente, el experimento de tweets apareados procura discriminar en qué medida la variación de una serie de componentes generados aleatoriamente, mediante la yuxtaposición de conjuntos de múltiples atributos, altera la propensión a compartir o descartar dicho contenido7 ${ }^{7}$ El experimento fue realizado por un total de 2.442 encuestados, quienes observaron pares de tweets cuyos atributos ${ }^{8}$ fueron aleatorizados utilizando código propietario del iLCSS (University of Maryland) y la herramienta de flujo de Qualtrics, con distribución realizada por Netquest. Una serie de trabajos previos han constatado que la propensión a compartir ciertos mensajes e ignorar otros resulta en la conformación de comunidades en redes sociales (Barberá, 2015) dentro de las cuales se co-construyen encuadres homogéneos (Aruguete, 2018; Aruguete; Calvo, 2018; Calvo; Aruguete, 2020).

\subsection{Diseño del instrumento: Componer un tweet combinando elementos de encuadre}

La pregunta fundamental que procura responder el modelo de network activated frames es ¿cómo se define y se crea un encuadre que es activado y propagado con distinta probabilidad por usuarios con preferencias disímiles? Para atender esta inquietud se parte de una hipótesis general: aquellos mensajes cuyos elementos de encuadre tienen resonancia en una comunidad, al estimular pensamientos particulares que se apliquen a los esquemas cognitivos de sus interlocutores, tendrán mayor probabilidad de ser aceptados y activados en cascada (Aruguete, 2019). Para evaluar el NAF, me enfocaré en la activación de elementos de encuadre en competencia por parte de los usuarios que aceptan dichos frames. La hi- 
pótesis nula sugiere que tanto los elementos de encuadre negativos (polarizantes) como los positivos (despolarizantes) tendrán el mismo efecto en la probabilidad de que el tweet sea compartido.

Para evaluar el efecto de distintos elementos de encuadre en la probabilidad de que las personas compartan un mensaje relativo a la Covid-19, se propone una operacionalización de la noción de encuadre que articula una serie de elementos expresados en los tweets -la definición de la situación, las causas implícitas del problema, el juicio moral y el remedio o la mejora futura- con el propósito de alcanzar precisión en el diseño de variables y categorías válidas y confiables. En el experimento de tweets apareados trabajado aquí, los elementos de encuadre que buscan medir la reacción de los encuestados quedan plasmados en:

- el mensaje lingüístico-verbal del posteo (mensajes negativos o polarizantes vs. mensajes positivos o de colaboración interpartidaria);

- el emisor del tweet [efecto de autoridad (endorsement)];

- las imágenes (polarizantes o de colaboración);

- la aceptación y apoyo hacia el contenido por parte de otros usuarios (que se observa en la cantidad de likes y retweets).

\subsubsection{Diseño}

Los conjoints experiments ${ }^{9}$ son una estrategia experimental en la cual cada encuestado es expuesto a dos mensajes cuyos contenidos son aleatoriamente rotados. Los encuestados luego responden una serie de preguntas que miden su preferencia por uno de los dos mensajes. En el caso de los tweets, para maximizar la validez interna y externa, el diseño experimental recrea dichos posteos combinando cuatro distintas secciones (encabezado, texto, imagen, pie) en el tweet 1 (izquierda) y en el tweet 2 (derecha).

La figura 1 muestra un ejemplo de dos tweets apareados, los cuales combinan aleatoriamente estos cuatro elementos. Tras ser expuestos a los tweets, un total de 2.442 encuestados respondieron las siguientes preguntas:

1) ¿Cuál de estos tweets es más probable que usted comparta en su muro? (respuestas: tweet 1, tweet 2, ambos, ninguno);

2) ¿Cuál de estos tweets es más probable que usted no comparta en su muro? (Respuestas: tweet 1, tweet 2);

3) ¿Cuál de estos dos tweets espera que sea comentado en su noticiero favorito? (Respuestas: tweet 1, tweet 2);

4) ¿Cuál de estos dos tweets espera ver primero al ingresar a sus cuentas de redes sociales? (Respuestas: tweet 1 , tweet 2 , ninguno).

Cada una de estas preguntas busca estimar el efecto marginal de los distintos atributos en la probabilidad de compartir uno de los dos tweets.

Las preguntas (1) y (2) dan cuenta del proceso de activación en cascada (Aruguete, 2019; Aruguete; Calvo, 2018), mientras que las preguntas (3) y (4) buscan medir los sesgos de atención selectiva ${ }^{10}$ en el entorno del votante. En este artículo me enfocaré en la pregunta (2), dado que fuerza una respuesta de preferencia por uno de los dos tweets. Es decir, si un

\begin{tabular}{|c|}
\hline EJEMPLO DE TUITS APAREADOS (CONJOINT) \\
\hline TUIT 1 \\
\hline
\end{tabular}

(11) LA NACIÓN

Alberto Fernández: "Es hora de terminar con la grieta y ponerse a trabajar para cuidar la salud de los Argentinos".
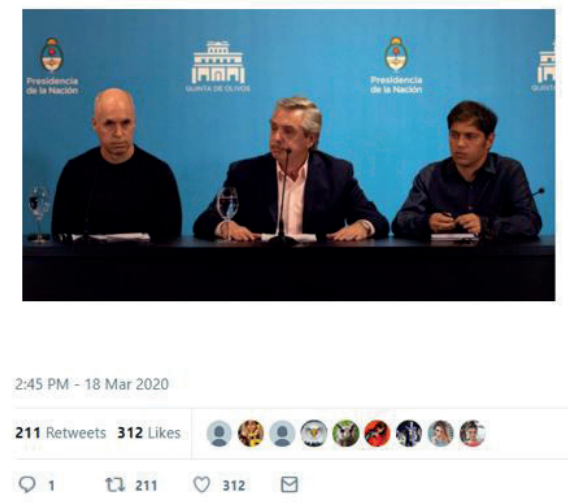

"Estamos así porque Macri prefirió financiar la salida de dólares en lugar de la inversión en hospitales", dice Alberto Fernández.

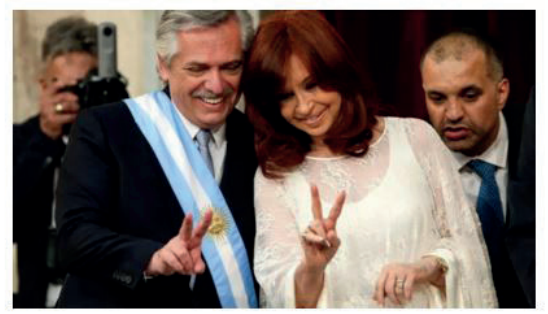

$$
\begin{aligned}
& \text { 2:45 PM - } 18 \text { Mar } 2020 \\
& 3 \text { Retweets } 2 \text { Likes } \quad 8000 \\
& \begin{array}{llll}
O_{1} & \mathrm{Zl}_{3} & \mathrm{O}_{2} & \square
\end{array}
\end{aligned}
$$

Figura 1. ¿Cuál de estos tweets es "menos probable que comparta en su muro"?

Nota: Ejemplo de tweets apareados tal y como fueron presentados a los encuestados. 
encuestado es expuesto a ambos tweets y responde que "nunca" compartiría el tweet 2, está expresando una preferencia débil por el tweet 1 . Vale la pena destacar que los resultados para las preguntas alternativas (1, 3 y 4) producen también resultados positivos. Sin embargo, las preguntas sobre el entorno no buscan medir la activación de contenido sino la "expectativa" de contenido activado. El análisis y la presentación de estos resultados son expuestos en otro artículo ${ }^{11}$.

\subsubsection{Elementos de encuadre}

La figura 2 describe el conjunto de elementos de encuadre que son incluidos y cuyas frecuencias son alteradas por los encuestados. Al aleatorizar los distintos elementos de encuadre que se observan en la figura 2, es posible medir la reacción de los encuestados a cada uno de dichos componentes. Así, algunos encuestados son expuestos a dos tweets de Página/12, uno a la izquierda (tweet 1) y otro a la derecha (tweet 2), mientras que otros observan tweets presuntamente publicados por La nación o alguna otra combinación de Página/12 y La nación. Lo mismo ocurre con los otros elementos de encuadre, lo que permite producir 192 combinaciones posibles (4 encabezados $x 4$ textos $\times 3$ imágenes $\times 4$ pies) que miden la reacción a cada componente.

Los elementos de encuadre que se observan en la figura 2 buscan constatar la preferencia de una persona por un medio más afín al oficialismo (Página/12) o a la oposición política ${ }^{12}$ (La nación). Desde el texto lingüístico-verbal, los usuarios son expuestos a alternativas de texto que polarizan ("Estamos así porque Macri prefirió financiar la salida de dólares en lugar de la inversión en hospitales") o textos que despolarizan ("Es hora de terminar con la grieta y ponerse a trabajar para cuidar la salud de los argentinos").

\subsubsection{Ejecución y estimación del modelo}

La encuesta fue implementada en Argentina entre marzo y abril de 2020. La encuesta fue programada en Qualtrics, con una muestra aleatorizada por Lapop-Vanderbilt sobre un panel de votantes adultos reclutado por Netquest. Un total de 2.442 encuestados respondieron las preguntas del experimento, permitiendo un poder muestral suficiente para detectar efectos significativos ${ }^{13}$. El modelo de conjoint se estimó como en Hainmueller, Hopkins y Yamamoto (2014), obteniendo estimados del efecto marginal de cada componente (average marginal component effect, AMCE); el "componente" describe aquí cada uno de los elementos de encuadre. Los componentes estaban balanceados entre las muestras, lo que queda garantizado por la herramienta de randomización de Qualtrics. Dado que los componentes del modelo de conjoint estaban propiamente aleatorizados, AMCE fue estimado utilizando mínimos cuadrados y, en este caso, los elementos de encuadre no fueron interactuados entre sí (Hainmueller; Hopkins; Yamamoto, 2014).

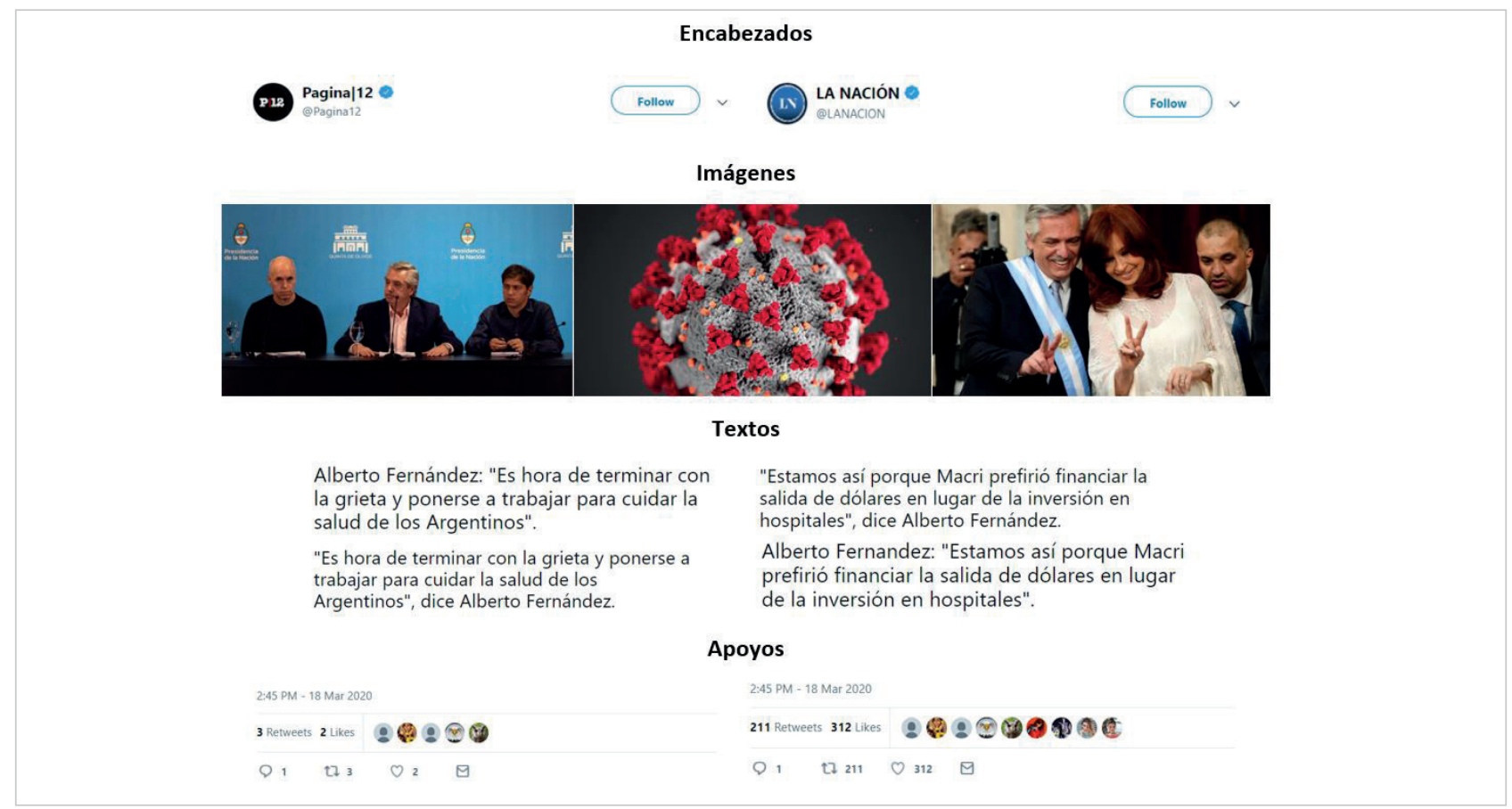

Figura 2. Elementos de encuadre en el experimento de tweets apareados (conjoint experiment).

Nota: El experimento de tweets apareados varía aleatoriamente los distintos elementos de encuadre, generando 192 combinaciones de autoría, textos, imágenes y apoyos (retweets y likes). 


\subsection{Hallazgos: polarizar o no polarizar, esa es la cuestión}

Realizar un experimento como este, cuyo propósito es medir de manera multidimensional y desagregada las preferencias de distintos atributos de un mensaje, en el marco de la Covid-19 es doblemente elocuente. En primer lugar, por tratarse de un fenómeno mundial que no discriminó entre sus afectados y cuya mitigación dependió, en gran medida, de las respuestas sanitarias de los gobiernos nacionales ${ }^{14}$. En este sentido, cabe destacar que el gobierno de Alberto Fernández (2019- ) reaccionó tempranamente y de manera mancomunada con los gobernadores de las provincias, mediante políticas públicas que priorizaron el cuidado sanitario de la población -tales como el aislamiento social preventivo y obligatorio (ASPO) y el distanciamiento social preventivo y obligatorio (DISPO)- y una inversión en el sistema de salud que lo previniera del colapso frente a la subida inminente de casos. Todo lo cual redundó en un crecimiento de su imagen positiva durante la primera etapa de la pandemia, coincidente con el período de la encuesta.

En segundo lugar, porque las formas de percibir la pandemia no fueron unívocas. Desde que el presidente Alberto Fernández declaró el ASPO el 19 de marzo, dos grandes preocupaciones escalaron en paralelo en la opinión pública. El crecimiento del temor a enfermarse coincidió con una elevada aprobación de la ciudadanía hacia la respuesta sanitaria del gobierno. La preocupación por perder el trabajo y verse afectados por la crisis económica que traía aparejada la Covid-19 también fue en ascenso hasta alcanzar un grado significativo de alarma. En efecto, los resultados obtenidos en el proyecto sobre "Transparencia, confianza y redes sociales" muestran que la percepción de riesgo sanitario no fue estable, sino que estuvo asociada a las posturas políticas y las identidades partidarias de los ciudadanos argentinos.

"Las mismas razones que explican las diferencias en preferencias políticas en distintos distritos electorales pueden ser, a su vez, las que expliquen las diferencias de creencias sanitarias y/o de comportamiento en distanciamiento social" (Aruguete; Calvo, 2020, p. 295).

En esta sección presento los estimados para tres modelos (los encuestados que votarían por Alberto Fernández si la segunda vuelta electoral "fuera la semana siguiente"; quienes elegirían a Mauricio Macri y aquellos que votarían en blanco). El propósito es ofrecer una comparación de las distintas interpretaciones que surgen de la exposición a los elementos de encuadre por parte de votantes de distintos partidos.

La tabla 1 y el gráfico 1 presentan resultados elocuentes de las reacciones a cada uno de los elementos de encuadre, tomando como variable independiente la intención de voto para cada uno de los tratamientos. Los datos de intención de voto resultan de responder la pregunta: “¿a quién votaría usted si la elección tuviera lugar la semana próxima?”, incluida en un módulo anterior al experimento. Respecto del primer elemento de encuadre que presentamos -la "autoridad" que emite el tweet (el diario oficialista, Página/12, o el opositor, La nación)-, el efecto experimental es modesto. En el caso de La nación, por ejemplo, es posible ver que su inclusión como autor del tweet tiene un efecto positivo, aunque leve, entre los votantes opositores de Mauricio Macri. En cambio, este periódico no produce un efecto de autoridad (endorsement) entre quienes votan por Alberto Fernández ni entre quienes dejarían su voto en blanco. En promedio, el efecto para toda la muestra es positivo aunque modesto y es considerablemente menor al reportado en datos observacionales que circulan en la red social Twitter. Cabe aclarar, en este punto, que si se midiera el efecto de autoridad con figuras políticas de peso, como el ex presidente Mauricio Macri (@mauriciomacri) o el actual mandatario, Alberto Fernández (@alferdez), el efecto sería considerablemente mayor que el observado con dos medios tradicionales con perfiles editoriales opuestos.

Tabla 1. Efecto marginal de los elementos de encuadre en la decisión de compartir el tweet

\begin{tabular}{|c|c|c|c|c|}
\hline & $\begin{array}{l}\text { All } \\
\text { (1) }\end{array}$ & $\begin{array}{c}\text { Fernández } \\
\text { (2) }\end{array}$ & $\begin{array}{l}\text { Independientes } \\
\text { (3) }\end{array}$ & $\begin{array}{l}\text { Macri } \\
(4)\end{array}$ \\
\hline Constante & $\begin{array}{c}0,460 * * * \\
(0,014)\end{array}$ & $\begin{array}{c}0,552^{* * *} \\
(0,024)\end{array}$ & $\begin{array}{c}0,368^{* * *} \\
(0,027)\end{array}$ & $\begin{array}{c}0,420 * * * \\
(0,019)\end{array}$ \\
\hline $\begin{array}{l}\text { Página/12 } \\
\text { (izquierda) }\end{array}$ & $\begin{array}{l}-0,020 \\
(0,012)\end{array}$ & $\begin{array}{l}-0,018 \\
(0,022)\end{array}$ & $\begin{array}{l}-0,027 \\
(0,024)\end{array}$ & $\begin{array}{l}-0,015 \\
(0,017)\end{array}$ \\
\hline Texto: Mensaje polarizante & $\begin{array}{c}-0,344^{* * *} \\
(0,012)\end{array}$ & $\begin{array}{c}-0,384^{* * *} \\
(0,022)\end{array}$ & $\begin{array}{c}-0,265^{* * *} \\
(0,024)\end{array}$ & $\begin{array}{c}-0,342^{* * *} \\
(0,017)\end{array}$ \\
\hline Imagen: Fernández y Larreta & $\begin{array}{c}0,012 \\
(0,015)\end{array}$ & $\begin{array}{c}0,080^{* * *} \\
(0,026\end{array}$ & $\begin{array}{l}-0,021 \\
(0,029)\end{array}$ & $\begin{array}{c}-0,043^{* *} \\
(0,021)\end{array}$ \\
\hline Imagen: Fernández y Kirchner & $\begin{array}{c}-0,080^{* * *} \\
(0,015)\end{array}$ & $\begin{array}{l}-0,013 \\
(0,027\end{array}$ & $\begin{array}{c}-0,109 * * * \\
(0,029)\end{array}$ & $\begin{array}{c}-0,122^{* *} \\
(0,021)\end{array}$ \\
\hline Pie: Alto apoyo & $\begin{array}{c}0,001 \\
(0,012)\end{array}$ & $\begin{array}{l}-0,010 \\
(0,022)\end{array}$ & $\begin{array}{l}-0,005 \\
(0,024)\end{array}$ & $\begin{array}{c}0,009 \\
(0,017)\end{array}$ \\
\hline $\begin{array}{l}N \\
\text { Adj } \mathrm{R}^{2}\end{array}$ & $\begin{array}{l}4.290 \\
0,159\end{array}$ & $\begin{array}{l}1.646 \\
0,164\end{array}$ & $\begin{array}{c}918 \\
0,126\end{array}$ & $\begin{array}{l}1.726 \\
0,193\end{array}$ \\
\hline
\end{tabular}

Nota: ${ }^{*} p<0,1 ; * *<0,05 ; * * *<<0,01$. Estimación de AMCE para observaciones aleatorizadas en forma independiente de acuerdo con Hainmueller Hopkins y Yamamoto (2014). Efectos marginales de cada elemento de encuadre en la probabilidad de preferir un tweet de los dos ofrecidos. La preferencia de los encuestados tiene una connotación "débil", ya que afirman que es "menos probable" que comparta el tweet 2. La preferencia débil es una forma de forzar una respuesta y, por ende, distingue la preferencia existente entre ambos tweets. 


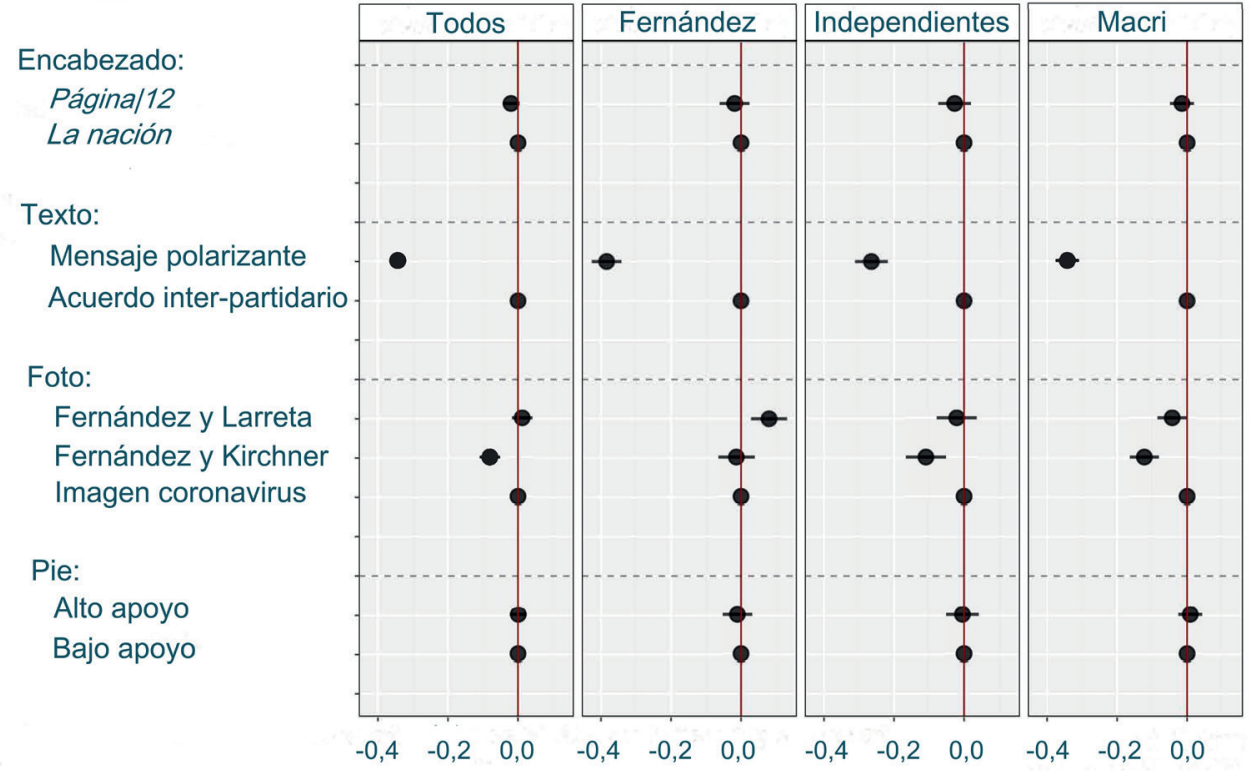

Gráfico 1. Efecto marginal de los elementos de encuadre en la decisión de compartir el tweet

La diferencia entre los datos experimentales y los datos observacionales es teóricamente relevante, por cuanto confirma que el efecto de endorsement de los medios en redes sociales está sobrerrepresentado (Aruguete; Calvo, 2018; Barberá, 2015; Calvo; Aruguete, 2020; Aruguete; Calvo; Ventura, 2020). En otras palabras, la propagación de mensajes de medios tradicionales no resulta tanto de su efecto noticioso sobre otros usuarios, sino de la sobrerrepresentación de dicho emisor, como resultado de la interacción entre el contenido del mensaje emitido y la comunidad que lo recibe.

A diferencia del modesto efecto de endorsement de ambos medios (Página/12 y La nación), el texto lingüístico-verbal contiene el elemento de encuadre que mayor efecto genera en la interpretación del mensaje y, como consecuencia, en la propensión de los encuestados a compartir el tweet. El mensaje que delega la responsabilidad de la crisis en Mauricio Macri ("toma de deuda en detrimento de inversión en hospitales"), en lugar de aquel que llama a colaborar con la oposición ("cerrar la grieta"), tiene un efecto negativo que es estadísticamente significativo ya que disminuye la tasa de retweeteo en un 70\%, un cambio en los odds-ratio igual a exp(-1,22)=0,+-295. El efecto de la negatividad de ese mensaje es más pronunciado entre quienes votarían por Macri en una segunda vuelta ( $78 \%$ de disminución en tasa de retweeteo) que entre los votantes de Fernández (68\% de disminución).

Otro hallazgo revelador es el efecto que provocan las imágenes (la que presenta colaboración entre partidos vs. la que reafirma la identidad intra-partidaria), presentadas en la figura 2, que fueron rotadas en el experimento. Al mantener como categoría base la imagen del virus Covid-19, los resultados muestran que los votantes de Mauricio Macri disminuyen significativamente su preferencia por un tweet que contiene la foto de Cristina Fernández (67\% de disminución) mientras que, para quienes votan por Alberto Fernández, la tasa de retweeteo no se incrementa. Más interesante aún, el efecto de la imagen del presidente Alberto Fernández con el jefe de gobierno de la Ciudad de Buenos Aires, Rodríguez Larreta, es también negativa entre los votantes opositores (34\% de disminución).

La diferencia entre el efecto positivo del texto colaborativo "cerrar la grieta y superar la polarización para trabajar en conjunto" y el efecto negativo de la foto de Alberto Fernández con Rodríguez Larreta es importante. Aun cuando los votantes de Macri vean con buenos ojos los mensajes colaborativos que extienden la mano, ello no altera su percepción negativa sobre Alberto Fernández. Otro dato relevante para este estudio es que la imagen negativa de Cristina Fernández entre los votantes en blanco es de similar magnitud y dirección que entre los votantes del Macrismo. En cambio, como es de esperar, la foto de Alberto Fernández con Rodríguez Larreta no tiene un efecto estadísticamente significativo entre los independientes. Finalmente, los valores no significativos para la cantidad de retweets y likes indican que el apoyo de otros usuarios reportado al pie del tweet (tanto retweets como likes) no es una información que los usuarios asocien a sus preferencias; es decir, la probabilidad de compartir el mensaje no aumenta por "seguir a las multitudes".

En definitiva, mientras que los efectos de autoridad y los de apoyo (likes y retweets) son insignificantes, es destacable la influencia sustantiva y estadísticamente significativa que genera la llamada a colaborar con otros partidos, tanto en el texto lingüístico-verbal cuanto en las imágenes que componen los mensajes. Estos resultados ponen de manifiesto dos dimensiones complementarias del framing process en el actual escenario mediático:

- constatan que ciertos elementos de encuadre generan reacciones entre los usuarios que influyen en la dirección y la frecuencia que toman esos mensajes;

- comprueban la hipótesis teórica de que la atención selectiva por parte de los usuarios y la activación en cascada de los mensajes que esos usuarios observan y aceptan son las dos caras del framing en redes sociales. 


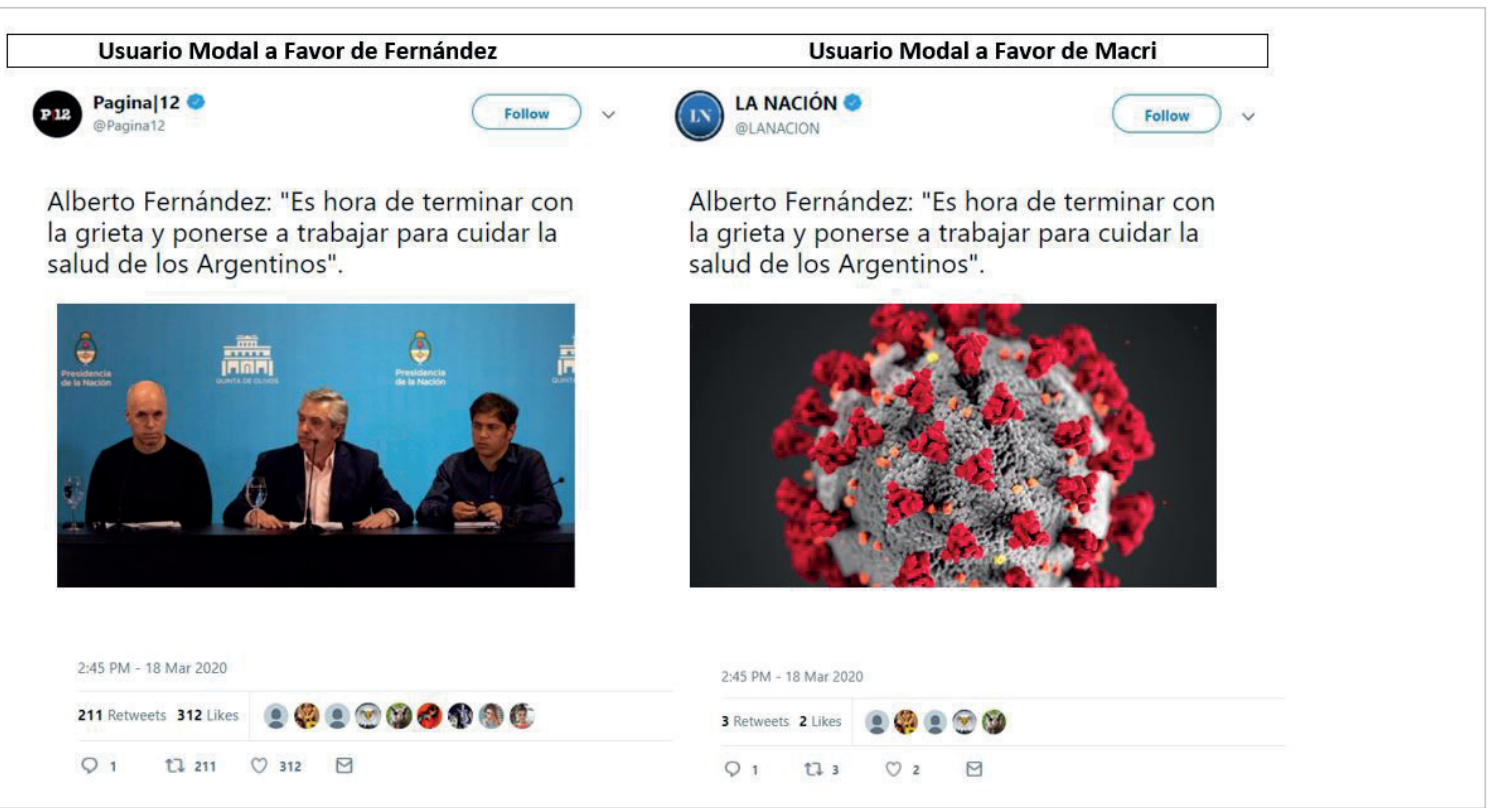

Figura 3. El tweet modal en la comunidad pro-Fernández (izquierda) y pro-Macri (derecha)

Más concretamente, dejan en evidencia que aquellos mensajes que resulten resonantes tendrán más probabilidad de ser aceptados y activados en cascada y, como consecuencia, cambiará su frecuencia de circulación en las comunidades virtuales habitadas por tales usuarios.

\subsection{Combinación modal de elementos de encuadre en la comunidad oficialista y opositora}

El modelo de network activated frames asume que la activación de distintos elementos de encuadre por parte de usuarios ubicados en distintas regiones de la red, comunica encuadres que se distinguen localmente. Es decir, encuadres que son observados con distinta probabilidad por usuarios interconectados que integran comunidades virtuales. El análisis de los tweets apareados (conjoint analysis) mostrado en la sección anterior evidencia que, por ejemplo, mensajes con textos negativos (polarizantes) que, además, tienen la foto de la ex-presidente Cristina Fernández (refuerzo de identidad partidaria) deberían estar sub-representados en la red, dado que ambos elementos de encuadre, texto e imagen, disminuyen la probabilidad de que el mensaje sea compartido. El efecto de ese tipo de narrativa es más pronunciado entre los usuarios que votarían por Mauricio Macri. En definitiva, la foto de Cristina será activada con poca frecuencia entre los votantes de Fernández y, menos aún, entre quienes eligieron a Macri.

Un ejercicio interesante sería utilizar los resultados del experimento de tweets apareados para representar el encuadre "modal" entre los votantes de cada partido. El NAF asume que las narrativas tienen una probabilidad diferencial de ser observadas en distintas regiones de la red; en cambio, la activación más frecuente -esto es, el valor modal- haría que los tweets de la figura 4 estuvieran sobre-representados en el centro de cada comunidad. En el encuadre modal representado en esta imagen, por caso, en ambas comunidades circula el mismo texto lingüístico-verbal ("cerrar la grieta") aunque con distintas imágenes incluidas en cada tweet. Entre quienes votarían por Fernández es más probable ver un posteo compuesto por Larreta>CFK>Virus, mientras que en la comunidad de apoyo a Macri lo previsible sería ver un mensaje que incluya Virus>Larreta>CFK (CFK = Cristina Fernández de Kirchner). El tweet modal, en definitiva, presenta preponderantemente una imagen de colaboración entre los votantes afines al gobierno nacional, considerando que el texto se ve reforzado por una imagen colaborativa.

En los muros de los usuarios, la activación de encuadres en red presenta una imagen coherente que se alinea con sus preferencias y es distinta a la observada en la otra comunidad. Más importante aún es notar que la probabilidad inicial de los distintos elementos de encuadre era idéntica en diseño, aunque distinta una vez que fuera activada por los encuestados. Por ejemplo, aun cuando la probabilidad de que un votante de Macri “observara” una foto de Cristina Fernández era del 33,33\%, la activación del contenido por parte de los usuarios redundó en una variación en la probabilidad de que sus contactos observen dicha información en la red. Por lo tanto, en su forma modal, los votantes de Mauricio Macri y de Alberto Fernández fueron expuestos a encuadres distintos a raíz de dicha activación.

\section{Discusión: logros y limitaciones de este estudio}

En esta sección se discuten dos de las contribuciones de este estudio, aunque también se incluyen sus limitaciones: Se discute:

- cuál es el efecto del framing en la interpretación de la pandemia Covid-19 por parte de la ciudadanía argentina;

- las implicaciones teóricas de la activación de ciertos encuadres en redes sociales, constatadas en el experimento de encuestas presentado aquí; 
- las limitaciones de un estudio experimental, las limitaciones de los elementos rotados experimentalmente y las limitaciones del formato de presentación de los contenidos (Twitter vs. Facebook).

\subsection{Encuadre del riesgo en la Covid-19}

Las palabras e imágenes que componen un encuadre pueden ser distinguidas de las demás noticias por su capacidad para estimular apoyo u oposición a los distintos campos de un conflicto político (Entman, 2003). La expresión de Entman es productiva para entender que, lejos de ser un asunto unidimensional, la Covid-19 acoge múltiples definiciones, así como responsabilizaciones y soluciones disímiles, que son acordes con las percepciones de polarización afectiva existentes en varios países del mundo (Iyengar et al., 2019). En los primeros meses de 2020, algunos discursos gubernamentales han encuadrado sus respuestas a la pandemia como las mejores políticas en pos de minimizar los costos sanitarios y/o económicos para la ciudadanía de sus naciones. La oposición, en la gran mayoría de estos países, se ha enfocado en las áreas más débiles de dichas respuestas. En Argentina, concretamente, donde el gobierno se ha concentrado en dar una respuesta sanitaria a la crisis en forma coordinada con los gobiernos provinciales, la oposición ha enfatizado los efectos económicos de la pandemia (Aruguete; Calvo, 2020). El denominador común es que los ciudadanos han internalizado encuadres políticos al momento de encuadrar la crisis ocasionada por la Covid-19 y que estos redundaron en una disminución del apoyo a la política sanitaria del gobierno. En otras palabras, configurar discursivamente la pandemia en términos de "Peronismo y salud" (esto es, activando la identidad partidaria del partido de gobierno) encuadra la respuesta sanitaria oficial de un modo distinto que presentarlo como forma de "colaboración inter-partidaria y salud". La probabilidad de aceptar y compartir encuadres comunicacionales se ve resentida frente a mensajes negativos que atacan al "otro", aunque también por avales (endorsement) e imágenes que promueven, en mayor o menor medida, una respuesta identitaria por parte de los votantes.

\subsection{Activación de encuadres en el nuevo entorno mediático}

Las concepciones de integralidad del framing que se han mostrado aquí -reunir y encajar en- son provechosas para abordar, de manera consistente, objetivos empíricos y procedimientos metodológicos que comprendan las distintas etapas del proceso de circulación de sentido. En el nuevo escenario virtual es aún más rico estudiar la producción y activación de encuadres, aunque cabe reconsiderar ciertos parámetros de análisis y proponer nuevos.

En este artículo me he preguntado acerca del potencial de los marcos interpretativos de los textos para volver aplicables y, por lo tanto, activar elementos distintivos de los conocimientos almacenados en la memoria de los lectores. Es en esta línea donde propongo resignificar el modelo de activación en cascada tal como ha sido propuesto por Entman, en vistas del nuevo escenario comunicacional, dado que refiere a un mecanismo de activación y/o desafío de los encuadres oficiales en un sistema comunicacional jerárquico y estratificado. En su lugar, se propone el network activated frames (NAF), un modelo que permite comprender la activación en cascada como un proceso de composición colectiva de encuadres que resulta de las reacciones individuales de usuarios conectados a una red.

La activación de narrativas en redes sociales puede ser estudiada desde el modelo de activación del conocimiento (Price; Tewksbury, 1997), según el cual los individuos dejan ingresar determinados dispositivos narrativos con los que actualizan los esquemas individuales y completan vacíos en la información. Este comportamiento subjetivo tiene consecuencias topológicas. En la medida en que los usuarios aceptan y republican ciertos contenidos, alteran la frecuencia con la que ellos mismos observan palabras, links y hashtags, al tiempo que los vuelven visibles en el muro de sus pares conectados.

En efecto, al seguir a aquellos "amigos" que son como nosotros recibimos una versión aumentada de la información que a ellos les gusta y que, por lo tanto, queda habilitada en nuestro muro. Esa conformación colectiva de agendas y encuadres no niega la existencia de jerarquías en las redes. Por el contrario, los actores que ya detentaban poder en el escenario no virtual lo consolidan en estas plataformas. En virtud de esa estructura jerárquica, los elementos de encuadre con los que tenemos afinidad volverán cual cámara de eco y quedarán sobrerrepresentados entre nuestros contactos inmediatos y, en consecuencia, se propagarán con menor resistencia.

Sin embargo, el que una autoridad en la red proponga un determinado marco al definir un asunto no garantiza que los usuarios lo acojan. La conformación de encuadres en distintas regiones de la red dependerá de que se activen mensajes que son ofrecidos - no impuestos- por las autoridades. Más aún, las autoridades no son siempre las mismas, sino que su posición en la red, así como su potencial de apropiarse de los encuadres dominantes puede variar en función de las rotaciones que se produzcan a partir del diálogo activado por ciertos temas en determinados contextos. El mundo discursivo que compartimos guarda coherencia desde el momento mismo en el que los contactos que habilitamos para transmitir información comunican contenidos que son consistentes entre sí y, más aún, compatibles con nuestras preferencias y creencias. Lo que originalmente fue atención selectiva, eventualmente deviene encuadre interpretativo y comunidad de información. Con el paso del tiempo, nuestros mundos informativos se mimetizan con los de nuestros amigos virtuales (Calvo; Aruguete, 2020).

En resumen, en este trabajo teórico-empírico se propone la activación de encuadres en red (NAF) como un modelo que permite explicar cómo se estructura un encuadre local de manera dinámica y reticular y, como contracara, advertir que tales encuadres no descienden ni son disputados en sistemas comunicacionales verticales con jerarquías predetermi- 


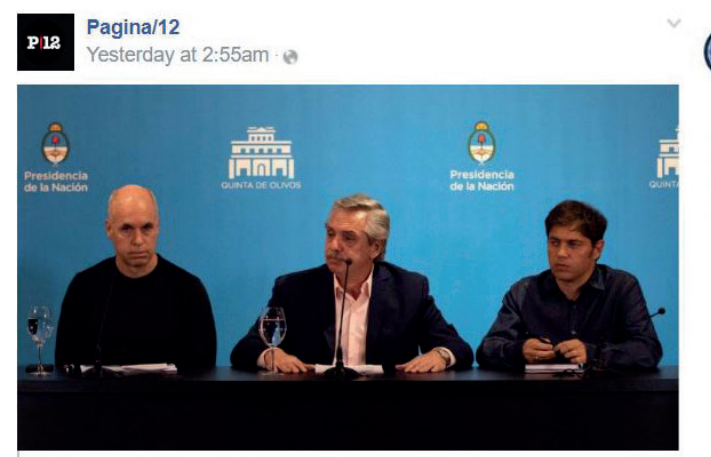

Alberto Fernandez: "Es hora de terminar con la grieta y ponerse a trabajar para cuidar la salud de los Argentinos.

Like · Comment · Share

4 people like this.

$\Rightarrow 12$ shares

Write a comment ..
LA NACIÓN

@LANACION

Alberto Fernández: "Es hora de terminar con

la grieta y ponerse a trabajar para cuidar la salud de los Argentinos".

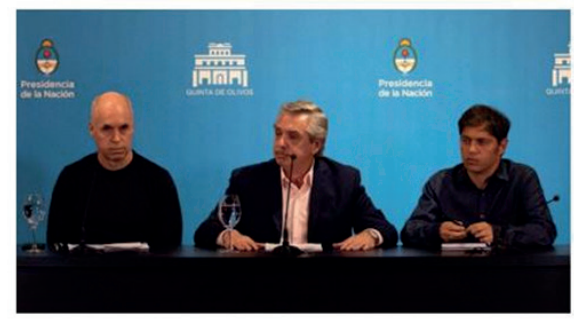

2:45 PM - 18 Mar 2020

211 Retweets 312 Likes 2802030

Q 1 [2 $211 \quad \mathrm{O}_{312} \quad$ घ

Figura 4. Facebook (izquierda) vs. Twitter (derecha), tal como se vería en el experimento.

Nota: Diferencias en la información si el experimento hubiese sido realizado en Facebook comparado con Twitter.

nadas, sino que se van construyendo colectivamente a partir de decisiones individuales -condicionadas por estructuras orgánicas- de aceptar o ignorar contenidos en tanto y en cuanto estos tengan resonancia con sus cosmovisiones.

\subsection{Limitaciones de este estudio}

Todo estudio tiene sus limitaciones y es importante destacar cuales son los puntos ciegos en un análisis experimental de la activación de contenidos en red (NAF). En esta sección destacamos dos importantes decisiones metodológicas que son siempre relevantes: validez externa y selección de red.

La decisión de evaluar experimentalmente la activación de contenidos en red tiene muchas ventajas comparativas respecto de la data observacional. La más importante es la validez interna que resulta de tener control experimental sobre lo que observa un encuestado. La mayor validez interna de los experimentos, sin embargo, también puede estar acompañada de una menor validez externa, en la medida en que la información experimental es presentada a los usuarios en un contexto que es distinto al observado en su vida cotidiana. En Twitter y Facebook, por ejemplo, los posteos aparecen en forma secuencial (arriba/abajo) en lugar de hacerlo en competencia (izquierda/derecha). Más importante aún, el hecho de presentar dos tweets aislados del contexto de un muro aumenta el nivel de atención de los usuarios. En efecto, la tasa de likes y retweets en estudios experimentales es mayor que en los datos observacionales (Calvo; Ventura, 2020).

Por tanto, si bien el análisis experimental en este artículo mantiene validez interna y compara dos tweets que sólo varían en sus elementos de encuadre, también "activan" con mayor frecuencia que en los datos observacionales. El estudio de activación del NAF en su forma experimental, evalúa apropiadamente la congruencia normativa, pero exagera la activación que resulta de dicha congruencia.

Otra limitación de este estudio es la decisión de ofrecer a los encuestados un formato de mensaje en red que corresponde a Twitter, en lugar de utilizar un formato de Facebook, Instagram u otra plataforma. La figura 4 permite contextualizar la importancia de esta decisión y entender cómo difiere la presentación de contenidos en ambas plataformas. En este ejemplo, el mismo mensaje es presentado usando el formato de Facebook (izquierda) y el formato de Twitter (derecha). Como es posible observar, el formato de Facebook le otorga mayor centralidad a la imagen y menor importancia al texto. Por lo tanto, efectos de orden y primacía visual deberían verse afectados. Nuevamente, esto no altera la validez interna del experimento y los resultados del NAF, aunque modifica las frecuencias de activación reportadas experimentalmente.

Finalmente, la validez externa del experimento también es menor debido a que la probabilidad de que un contenido sea observado por los encuestados es fija y no depende de sus conectividades en red. En este caso, sin embargo, mejorar la validez externa del experimento atentaría contra su validez interna, dado que el objetivo es precisamente comprender la activación diferenciada de contenidos cuando las probabilidades iniciales son las mismas.

\section{Notas}

1. Las "autoridades de redes sociales" son autores de mensajes que, dado su nivel jerárquico, tienen la capacidad de propagar información a mayor velocidad y alcance, ayudados además por la influencia de sus narrativas. 
2. Habermas (2002, p. 179) define el mundo de la vida como

"el lugar trascendental en que hablante y oyente salen al encuentro; en que pueden plantearse recíprocamente la pretensión de que sus emisiones concuerdan con el mundo (con el mundo objetivo, con el mundo subjetivo y con el mundo social)".

3. En este trabajo, se usarán los términos "frame", "encuadre", "marco" y "enfoque" indistintamente.

4. Antes que Bateson y Goffman, otra serie de aportes también contribuyeron a explicar los procesos de contextualización de la información y el framing en comunicación. En 1869, James dio "un giro fenomenológico subversivo" (Goffman, 2006 , p. 2). En lugar de preguntarse qué cosa es la realidad, James sugiere pensar en qué circunstancias creemos que las cosas son reales. Lo importante de la realidad, asume James, es nuestra sensación de su ser real. Y ello depende de nuestra atención selectiva, del compromiso íntimo y de la no contradicción con lo que hemos conocido de otra manera.

5. La polarización afectiva ocurre cuando los individuos perciben una separación entre grupos políticos o sociales (Yang et al., 2016). La polarización de actitudes se da cuando un individuo se mueve hacia una posición más extrema (Lord; Ross; Lepper, 1979).

6. Un cambio reciente de política en Twitter también habilita la publicación de tweets que son gustados (like) en el muro de nuestros pares.

7. El caso planteado aquí forma parte de una encuesta sobre confianza y percepción de riesgo realizada en el marco de la pandemia por Covid-19, en colaboración con la University of Maryland, la Vanderbilt University y el Banco Interamericano de Desarrollo (del 23 de marzo al 8 de mayo de 2020). Participaron 2.442 encuestados (todos respondieron al experimento) que fueron reclutados por Netquest, con selección probabilística realizada por Lapop-Vanderbilt para el proyecto Transparency, trust, and social media (Transparencia, confianza y redes sociales) (BID: 1300600-01-PEC). Los encuestados respondieron la encuesta de manera online.

8. En un experimento de encuestas, cada "tratamiento" describe un subgrupo que recibe determinada información, distinta a la que se le entrega a otro. El objetivo es comparar el efecto de distintos encuadres en la interpretación de ambos grupos de encuestados.

9. Para una discusión general sobre conjoint experiments ver Green, Krieger y Wind (2001).

10. Como ya se ha mencionado, la atención selectiva en redes sociales indica que prestamos atención a algunos usuarios y temas, en perjuicio de otros usuarios a los que podríamos seguir e infinidad de asuntos con los que tendríamos oportunidad de interactuar.

11. La diferencia entre compartir contenido (self) y las expectativas de ver contenidos compartidos (efecto de pares) es una variante de la llamada "paradoja de los amigos" (Feld, 1991).

12. En cuanto a la autoridad de los posteos, diversos trabajos han evidenciado que el diario Página/12 asumió una posición editorial cercana al Peronismo -y, en particular, al Kirchnerismo- desde 2003 hasta la actualidad, independientemente de que estos partidos estuvieran o no en ejercicio del poder. El diario La nación, por su parte, tuvo una cobertura opositora al Peronismo-kirchnerista desde 2008, cuando se desató el llamado "conflicto del campo", en adelante (Zunino, 2016, 2019).

13. El tamaño de la muestra excede cómodamente los requerimientos de poder muestrales para detectar efectos significativos.

14. La evolución de la pandemia y las respuestas sanitarias de los gobiernos, a su vez, permitieron realizar estudios comparados en el marco del proyecto citado aquí.

\section{Referencias}

Anderson, John-Robert (1983). The architecture of cognition. Harvard University Press. ISBN: 9780805822335

Ardèvol-Abreu, Alberto (2015) “Framing o teoría del encuadre en comunicación. Orígenes, desarrollo y panorama actual en España". Revista latina de comunicación social, n. 70, pp. 423-450.

https://doi.org/10.4185/RLCS-2015-1053

Aruguete, Natalia (2018). “\#2X1: Diálogos al costado de la grieta”. Intersecciones en comunicación, n. 12, pp. 35-48. https://www.ridaa.unicen.edu.ar/xmlui/handle/123456789/2313

Aruguete, Natalia (2019). "Network-activated frames (NAF), redefining framing in a new digital era". Encyclopedia of educational innovation. Singapore: Springer Nature. ISBN: 9789811322624

https://doi.org/10.1007/978-981-13-2262-4_55-1

Aruguete, Natalia; Calvo, Ernesto (2018). "Time to \#protest: Selective exposure, cascading activation, and framing in social media". Journal of communication, v. 68, n. 3, pp. 480-502.

https://doi.org/10.1093/joc/jqy007 
Aruguete, Natalia; Calvo, Ernesto (2020) “Coronavirus en Argentina: Polarización partidaria, encuadres mediáticos y temor al riesgo". Revista SAAP, v. 14, n. 2, pp. 281-310.

https://doi.org/10.46468/rsaap.14.2.A2

Aruguete, Natalia; Calvo, Ernesto; Ventura, Tiago (2020). "News sharing, gatekeeping, and polarization: A study of the \#Bolsonaro Election". Digital journalism, v. 9, n. 1.

https://doi.org/10.1080/21670811.2020.1852094

Bakshy, Eytan; Messing, Solomon; Adamic, Lada-Adriana (2015). “Exposure to ideologically diverse news and opinion on Facebook". Science, v. 348, n. 6239, pp. 1130-1132.

https://doi.org/10.1126/science.aaa1160

Barberá, Pablo (2015). "Birds of the same feather tweet together: Bayesian ideal point estimation using Twitter data". Political analysis, v. 23, n. 1, pp. 76-91.

https://doi.org/10.1093/pan/mpu011

Barberá, Pablo; Rivero, Gonzalo (2012). “¿Un tweet, un voto? Desigualdad en la discusión política en Twitter”. En: I Congreso Internacional en Comunicación Política y Estrategias de Campaña, pp. 200-220.

Bateson, Gregory (2000). Steps to an ecology of mind: Collected essays in anthropology, psychiatry, evolution, and epistemology. University of Chicago Press. ISBN: 9780226039053

Bennett, W. Lance (1990). "Toward a theory of press-state". Journal of communication, v. 40, n. 2, pp. 103-127. https://doi.org/10.1111/j.1460-2466.1990.tb02265.x

Bennett, W. Lance (1996). "An introduction to journalism norms and representations of politics". Political communication, v. 13, n. 4, pp. 373-384.

https://doi.org/10.1080/10584609.1996.9963126

Bechtel, Michael M.; Scheve, Kenneth F. (2013). "Mass support for global climate agreements depends on institutional design". Proceedings of the National Academy of Sciences, v. 110, n. 34, pp. 13763-13768.

https://doi.org/10.1073/pnas.1306374110

Bechtel, Michael M.; Hainmueller, Jens; Margalit, Yotam (2014). "Preferences for international redistribution: The divide over the Eurozone bailouts". American journal of political science, v. 58, n. 4, pp. 835-856.

https://doi.org/10.1111/ajps.12079

Berger, Peter-Ludwig; Luckmann, Thomas (1991). The social construction of reality: A treatise in the sociology of knowledge. Penguin Uk. ISBN: 9780140135480

Calvo, Ernesto; Aruguete, Natalia (2020). Fake news, trolls y otros encantos. Cómo funcionan (para bien y para mal) las redes sociales. Siglo XXI.

Calvo, Ernesto; Ventura, Tiago (2020). "Will I get Covid-19? Partisanship, social media frames, and perceptions of health risk in Brazil". Latin American politics and society, v. 63, n. 1.

https://doi.org/10.1017/lap.2020.30

Cardenal, Ana S.; Aguilar-Paredes, Carlos; Cristancho, Camilo; Majó-Vázquez, Silvia (2019). "Echo-chambers in online news consumption: Evidence from survey and navigation data in Spain". European journal of communication, v. 34, n. 4, pp. $360-376$. https://doi.org/10.1177/0267323119844409

Chong, Dennis; Druckman, James N. (2007). "A theory of framing and opinion formation in competitive elite environments". Journal of communication, v. 57, n. 1, pp. 99-118.

https://doi.org/10.1111/j.1460-2466.2006.00331.x

D’Angelo, Paul (2002). "News framing as a multiparadigmatic research program: A response to Entman". Journal of communication, v. 52, n. 4, pp. 870-888.

https://doi.org/10.1111/j.1460-2466.2002.tb02578.x

D’Angelo, Paul (2012). "Studying framing in political communication with an integrative approach". American behavioral scientist, v. 56, n. 3, pp. 353-364.

https://doi.org/10.1177/0002764211426332

Feld, Scott L. (1991). "Why your friends have more friends than you do?". American journal of sociology, v. 96, n. 6, pp. 1464-1477.

https://www.jstor.org/stable/2781907

Entman, Robert-Mathew (1993). "Framing: Toward clarification of a fractured paradigm". Journal of communication, v. 43, n. 4, pp. 51-58.

https://doi.org/10.1111/j.1460-2466.1993.tb01304.x 
Entman, Robert-Mathew (2003). "Cascading activation: Contesting the White House's frame after 9/11". Political communication, v. 20, n. 4, pp. 415-432.

https://doi.org/10.1080/10584600390244176

Entman, Robert-Mathew (2004). Projections of power: Framing news, public opinion, and US foreign policy. University of Chicago Press. ISBN: 9780226210728

Entman, Robert-Mathew; Usher, Nikki (2018). "Framing in a fractured democracy: Impacts of digital technology on ideology, power and cascading network activation". Journal of communication, v. 68, n. 2, pp. 298-308.

https://doi.org/10.1093/joc/jqy028

Festinger, Leon (1962). A theory of cognitive dissonance (v. 2). Stanford University Press. ISBN: 9780804709118

Franchino, Fabio; Zucchini, Francesco (2015). "Voting in a multi-dimensional space: A conjoint analysis employing valence and ideology attributes of candidates". Political science research and methods, v. 3, n. 2, p. 221-241.

https://doi.org/10.1017/psrm.2014.24

Gitlin, Todd (2003). The whole world is watching: Mass media in the making and unmaking of the new left. University of California Press. ISBN: 9780520239326

Goffman, Erving (2006). Frame analysis. Los marcos de la experiencia. Madrid: CIS. ISBN: 9788474764116

Green, Paul E.; Krieger, Abba M.; Wind, Yoram (2001). "Thirty years of conjoint analysis: Reflections and prospects". Informs. Journal on applied analytics, v. 31, n. 3_supplement, pp. 56-73.

https://doi.org/10.1287/inte.31.3s.56.9676

James, William (1869). "The perception of reality". In: James, William. Principles of psychology, v. 2. Dover Publications, pp. 283-324. ISBN: 9780486203812

Habermas, Jürgen (2002). Teoría de la acción comunicativa. II: Crítica de la razón funcionalista. Taurus. ISBN: 97884 30603404

Hainmueller, Jens; Hopkins, Daniel J. (2014). "Public attitudes toward immigration". Annual review of political science, v. 17 , pp. $225-249$.

https://doi.org/10.1146/annurev-polisci-102512-194818

Hainmueller, Jens; Hopkins, Daniel J.; Yamamoto, Teppei (2014). "Causal inference in conjoint analysis: Understanding multidimensional choices via stated preference experiments". Political analysis, v. 22, n. 1.

https://doi.org/10.1093/pan/mpt024

Hastie, Reid; Park, Bernadette (1986). "The relationship between memory and judgment depends on whether the task is memory-based or on-line". Psychological review, v. 93, n. 3, pp. 258-268.

https://doi.org/10.1037/0033-295X.93.3.258

Himelboim, Itai; Smith, Marc; Shneiderman, Ben (2013). "Tweeting apart: Applying network analysis to detect selective exposure clusters in Twitter". Communication methods and measures, v. 7, n. 3-4, pp. 195-223.

https://doi.org/10.1080/19312458.2013.813922

Horiuchi, Yusaku; Smith, Daniel M.; Yamamoto, Teppei (2017). "Measuring voters' multidimensional policy preferences with conjoint analysis: Application to Japan's 2014 election". Political analysis, v. 26, n. 2, pp. 190-209.

https://doi.org/10.1017/pan.2018.2

Iyengar, Shanto; Lelkes, Yphtach; Levendusky, Matthew; Malhotra, Neil; Westwood, Sean J. (2019). "The origins and consequences of affective polarization in the United States". Annual review of political science, v. 22, pp. 129-146. https://doi.org/10.1146/annurev-polisci-051117-073034

Kahneman, Daniel (2011). Thinking, fast and slow. Macmillan. ISBN: 9780374533557

Koziner, Nadia-Sabrina (2015). "El framing: un programa investigación para el estudio de las comunicaciones mediáticas". Animus. Revista interamericana de comunicação midiática, v. 14, n. 28, pp. 22-45.

https://doi.org/10.5902/2175497720203

López-Rabadán, Pablo; Vicente-Mariño, Miguel (2013). “Propuestas de consolidación teórica y analítica para los estudios de framing en la investigación sobre comunicación política". En: Estudios sobre comunicación política. Libro del año 2012. Madrid: Tecnos, pp. 239-259. ISBN: 9788430955305 https://doi.org/10.5209/ESMP.58022

Lord, Charles-George; Ross, Lee; Lepper, Mark-Roger (1979). "Biased assimilation and attitude polarization: The effects of prior theories on subsequently considered evidence". Journal of personality and social psychology, v. $37, \mathrm{n} .11, \mathrm{pp}$. 2098-2109.

https://doi.org/10.1037/0022-3514.37.11.2098 
Mason, Liliana (2013). "The rise of uncivil agreement: Issue versus behavioral polarization in the American electorate". American behavioral scientist, v. 57, n. 1, pp. 140-159.

https://doi.org/10.1177/0002764212463363

Mason, Liliana (2015). "I disrespectfully agree: The differential effects of partisan sorting on social and issue polarization". American journal of political science, v. 59, n. 1, pp. 128-145.

https://doi.org/10.1111/ajps.12089

Matthes, Jörg (2012). "Framing politics: An integrative approach". American behavioral scientist, v. 56, n. 3, pp. $247-259$. https://doi.org/10.1177/0002764211426324

Matthes, Jörg; Kohring, Matthias (2008). "The content analysis of media frames: Toward improving reliability and validity". Journal of communication, v. 58, n. 2, pp. 258-279.

https://doi.org/10.1111/j.1460-2466.2008.00384.x

Pariser, Eli (2011). The filter bubble: What the internet is hiding from you. Penguin UK. ISBN: 9780241954522

Price, Vincent; Tewksbury, David (1997). "News values and public opinion: A theoretical account of media priming and framing". In: Barnet, George A.; Boster, Franklin J. Progress in communication sciences, v. 13, pp. 173-212. ISBN: 9781 567503609

https://doi.org/10.1177/009365097024005002

Reese, Stephen (2007). "The framing project: A bridging model for media research revisited". Journal of communication, v. 57 , n. 1 , pp. $148-154$.

https://doi.org/10.1111/j.1460-2466.2006.00334.x

Rojas, Hernando; Barnidge, Matthew; Abril, Eulàlia P. (2016). "Egocentric publics and corrective action". Communication and the public, v. 1, n. 1, pp. 27-38.

https://doi.org/10.1177/2057047315619421

Sádaba, Teresa (2008). Framing: el encuadre de las noticias: el binomio terrorismo-medios. La Crujía. ISBN: 978987 6010283

Theocharis, Yannis; Barberá, Pablo; Fazekas, Zoltán; Popa, Sebastian-Adrian (2020). "The dynamics of political incivility on Twitter". Sage open, v. 10, n. 2, pp. 1-15.

https://doi.org/10.1177/2158244020919447

Tuchman, Gaye (1983). La producción de la noticia. Estudio sobre la construcción social de la realidad. Barcelona: Gustavo Gili.

Wojcieszak, Magdalena; Bimber, Bruce; Feldman, Lauren; Stroud, Natalie-Jomini (2016). "Partisan news and political participation: Exploring mediated relationships". Political communication, v. 33, n. 2, pp. 241-260.

https://doi.org/10.1080/10584609.2015.1051608

Yang, Jung-Hwan; Rojas, Hernando; Wojcieszak, Magdalena; Allberg, Toril; Coen, Sharon; Curran, James; Hayashi, Kaori; Iyengar, Shanto; Jones, Paul K.; Mazzoleni, Gianpietro; Papathanassopoulos, Stylanos; Rhee, June-Woong; Rowe, David; Soroka, Stuart; Tiffen, Rodney (2016). “Why are 'others' so polarized? Perceived political polarization and media use in 10 countries”. Journal of computer-mediated communication, v. 21, n. 5, pp. 349-367.

https://doi.org/10.1111/jcc4.12166

Yang, Tian; Majó-Vázquez, Silvia; Nielsen, Rasmus K.; González-Bailón, Sandra (2020). “Exposure to news grows less fragmented with increase in mobile access". Proceedings of the National Academy of Sciences of the United States of America, online first.

https://doi.org/10.1073/pnas.2006089117

Zunino, Esteban (2016). "The assessment of political news in the media agenda: a methodological proposal for more extensive content analysis". Communication \& society, v. 29, n. 4, pp. 235-254.

https://doi.org/10.15581/003.29.4.sp.235-254

Zunino, Esteban (2019). “¿Quién define la agenda? Las fuentes de información en la prensa digital argentina”. Comunicación y sociedad, año 16, e7394.

https://doi.org/10.32870/cys.v2019i0.7394 